九州大学学術情報リポジトリ

Kyushu University Institutional Repository

\title{
The significance of slippage in processing by high-pressure torsion
}

\section{Edalati, Kaveh}

Department of Materials Science and Engineering, Faculty of Engineering, Kyushu University

Horita, Zenji

Department of Materials Science and Engineering, Faculty of Engineering, Kyushu University

Langdon, Terence G.

Departments of Aerospace \& Mechanical Engineering and Materials Science, University of Southern California, Los Angeles | Materials Research Group, School of Engineering Sciences, University of Southampton

http://hdl. handle. net/2324/26383

出版情報: Scripta Materialia. 60 (1)，pp.9-12，2009-01. Elsevier バージョン：

権利関係 : (C) 2008 Acta Materialia Inc. 
Scripta Materialia 60 (2009) 9-12

Received 8 July 2008; Revised 11 August 2008; Accepted 11 August 2008

Available online 17 September 2008

\title{
The significance of slippage in processing by high-pressure torsion
}

\section{Kaveh Edalati , ${ }^{a}$ Zenji Horita ${ }^{\mathrm{a} *}$ and Terence G. Langdon ${ }^{\mathrm{b}, \mathrm{c}}$}

a Department of Materials Science and Engineering, Faculty of Engineering, Kyushu University, Fukuoka 819-0395, Japan

${ }^{\mathrm{b}}$ Departments of Aerospace \& Mechanical Engineering and Materials Science, University of Southern California, Los Angeles, CA 90089-1453, USA

${ }^{\mathrm{c}}$ Materials Research Group, School of Engineering Sciences, University of Southampton, Southampton SO17 1BJ, UK

\begin{abstract}
Experiments were conducted to measure the extent of slippage occurring when thin disks are processed by high-pressure torsion. Separate tests were conducted on aluminum, copper and iron. The results show the extent of slippage varies between these three materials such that there is very little slippage in aluminum, slightly more slippage in copper and significant slippage when using iron. For all materials, the extent of slippage increases at both faster rotational speeds and lower imposed pressures.
\end{abstract}

Keywords: High-pressure torsion; Severe plastic deformation; Slippage; Ultrafine grains.

* Corresponding author. Tel.: +81 92802 2958; fax: +81 92802 2992; e-mail: horita@zaiko.kyushu-u.ac.jp 
The application of severe plastic deformation (SPD) to coarse-grained solids is now an accepted procedure for producing very significant microstructural refinement with grains in the submicrometer or nanometer range [1,2]. Several techniques of SPD processing are available but most attention has been directed to the processes of equal-channel angular pressing (ECAP) [3] and high-pressure torsion (HPT) [4]. Furthermore, HPT is especially attractive because it produces ultrafine grain sizes that are smaller than those generally achieved using ECAP [5,6].

Processing by HPT is now attracting considerable attention because it has been recognized that the technique provides an opportunity not only for producing ultrafine-grained microstructures but also it may be used for a range of other applications. Examples of these other applications include using HPT for the consolidation of powders [7-16], for the consolidation of machining chips [17,18] and making use of the high pressures imposed in HPT to achieve phase transformations [19,20] or partial amorphization of bulk solids [21,22]. Recent experiments have demonstrated significant advantages in using titanium processed by HPT for use in medical implants because of the increased pre-osteoblast attachments and rates of growth that are a direct consequence of the nanostructural features of the HPT materials [23]. Furthermore, although HPT processing is generally used with thin disk samples, recent research has demonstrated the feasibility of extending the HPT process for use with small bulk cylindrical samples [24,25] and ring samples [26].

An important current question in processing by HPT concerns the significance of any slippage that may occur during the straining operation. Although it is generally recognized that the torsional straining of an HPT disk may not correspond precisely to the external rotation imposed during processing, there has been no attempt to date to conduct any detailed investigation to determine the precise difference between the imposed torsional rotation and the straining experienced by the sample. For the purposes of this investigation, slippage is defined explicitly as the difference between the measured torsional rotation of the disk and the rotation imposed externally by the processing facility. The present investigation was therefore initiated to provide the first direct measurements of slippage in HPT processing using three different metals as model materials and two different rotation speeds.

The principle of the HPT facility employed in this investigation is shown schematically in Fig. 1. The upper and lower anvils of the facility were made from high-strength tool steel with the surfaces nitrified. These two anvils were arranged in a vertical alignment and they contained, on their inner surfaces, small depressions carefully machined into the center of each anvil with diameters of $10 \mathrm{~mm}$ and depths of $0.25 \mathrm{~mm}$. The flat-bottomed surfaces of these two depressions were roughened to increase the frictional forces between the samples and the anvil surfaces. The HPT samples were in the form of thin disks having diameters of $10 \mathrm{~mm}$ and thicknesses of $0.8 \mathrm{~mm}$. For testing of a disk, the sample was placed in the depression on the lower anvil as shown on the left in Fig. 1 and the lower anvil was then raised so that the disk was contained between the two anvils under an external applied pressure, $P$, as shown on the right in Fig. 1. The application of this load led to a very small reduction in the specimen thickness with the magnitude of the reduction dependent upon the material and the applied pressure. It should be noted that a detailed 
description of the separate effects of external pressure and torsional straining in HPT processing is given elsewhere [27]. The type of HPT processing illustrated in Fig. 1 is generally termed quasi-constrained HPT because the sample is constrained within the depression and torsional straining takes place essentially in the presence of a back-pressure [28]. Torsional straining was achieved through rotation of the lower anvil, as indicated by the arrow on the right in Fig. 1.

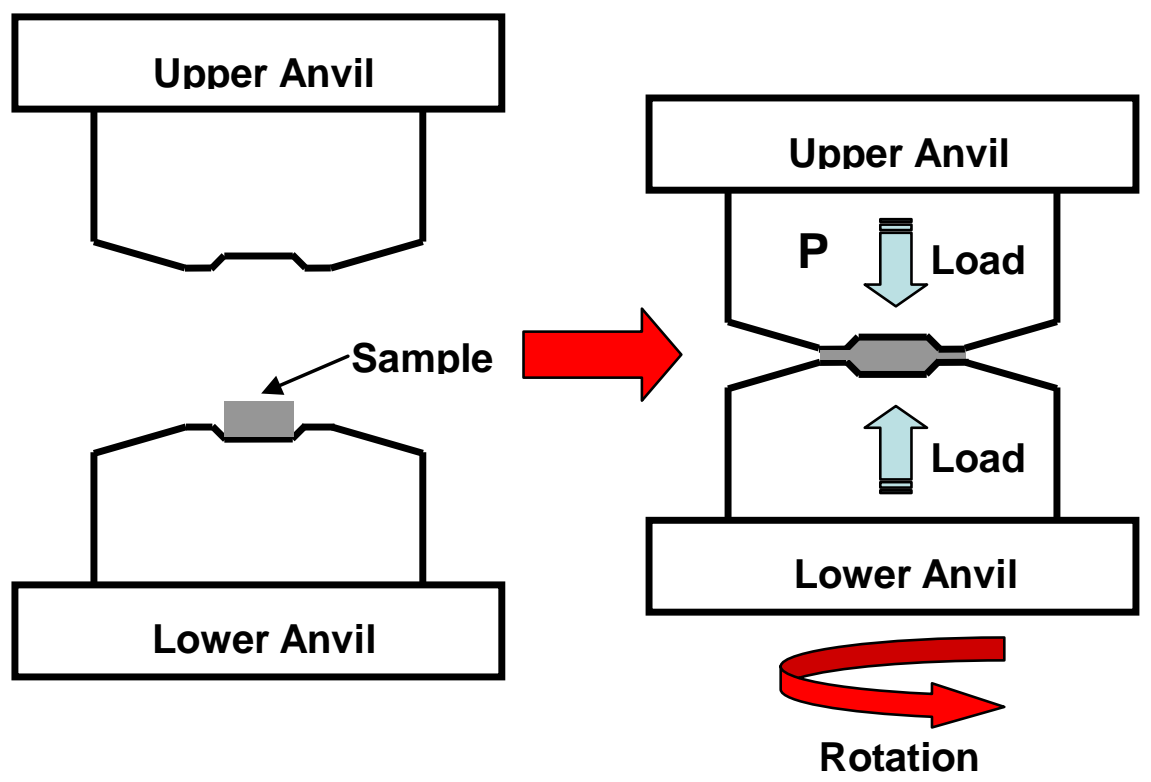

Fig. 1 Principle of the HPT facility.

All of the HPT processing conducted in this investigation was performed at room temperature using two new anvils in order to minimize the extent of any slippage. The tests were performed using disks of high-purity (99.99\%) Al, high-purity (99.99\%) Cu and pure (99.96\%) Fe. All of these materials were used in different earlier HPT investigations and details are available for $\mathrm{Al}$ [26], $\mathrm{Cu}$ [29] and $\mathrm{Fe}$ [30]. The $\mathrm{Al}$ was annealed for 1 hour at $773 \mathrm{~K}$ to give an initial grain size of $700 \mu \mathrm{m}$, the $\mathrm{Cu}$ was annealed for 1 hour at $873 \mathrm{~K}$ to give an initial grain size of $100 \mu \mathrm{m}$ and the Fe was annealed for 1 hour at $1273 \mathrm{~K}$ to give an initial grain size of $200 \mu \mathrm{m}$. The HPT processing was conducted using pressures, $P$, from 0.3 to $6.0 \mathrm{GPa}$ and rotation speeds of either 0.5 or $1.0 \mathrm{rpm}$.

The principle for measuring the strain in HPT processing is illustrated schematically in Fig. 2 where a disk of radius $r$ is subjected to a small torsional rotation $d \theta$. The consequent displacement at the upper outer perimeter of the disk is $d \ell$ where this is equivalent to $r d \theta$. Thus, the incremental shear strain, $d \gamma$, is given by $r d \theta / h$ where $h$ is the disk thickness.

In the present experiments, the objective was to measure the incremental rotation of the upper surface of each disk with respect to the lower surface, where this increment is equivalent to the displacement $d \ell$ in Fig. 2. Accordingly, a line was carefully scribed along the diameter of the disk and an identical and parallel line was also scribed on the other surface. The disk was then placed in the HPT facility and torsionally strained under the selected conditions of rotation speed and imposed pressure. Following straining, it was removed from the facility and the angle 
between the two lines was carefully measured. The difference between the measured angle and the anticipated angle was then recorded in terms of the fraction of slippage. Thus, a straining of $N$ $=0.25$ revolutions means that the disk is rotated by a distance equal to a quarter of the circumference and the anticipated angle between the two lines should be $90^{\circ}$. If the measured angle is $90^{\circ}$, there is no slippage during torsional straining and the slippage fraction is recorded as 0 . Alternatively, if the measured angle is $81^{\circ}$ instead of $90^{\circ}$, there is a slippage of $10 \%$ which is recorded as a slippage fraction of 0.1 .

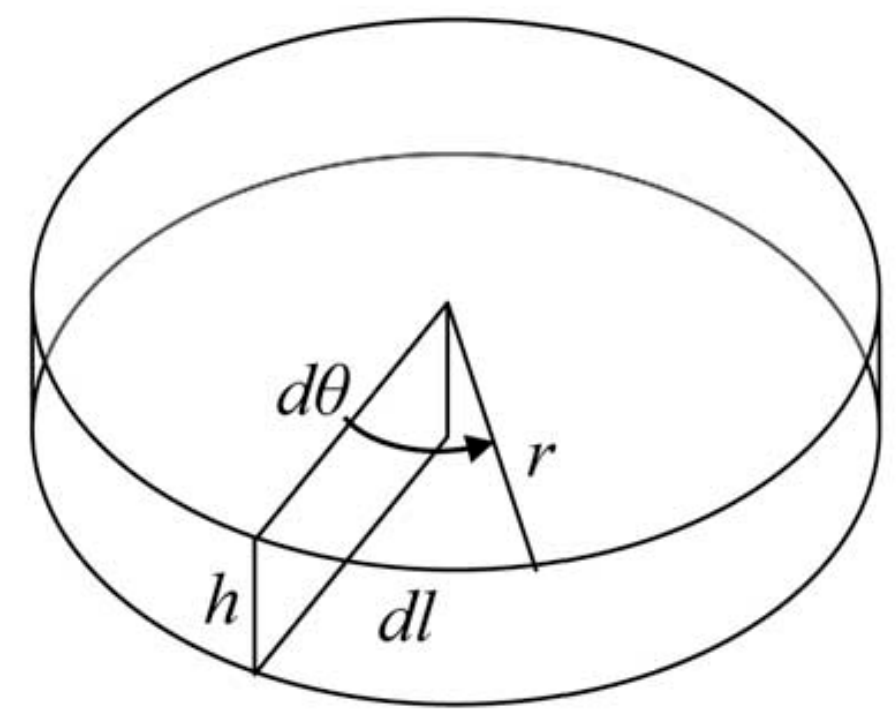

Fig. 2 The procedure for defining the strain imposed in HPT processing.

Some preliminary tests were performed with $\mathrm{Cu}$ disks to determine the significance of the number of revolutions, $N$, by imposing pressures of either 2.0 or $6.0 \mathrm{GPa}$ and testing separate disks through a range of revolutions from $N=0.125$ to $N=2.0$. The results from these tests are shown in Fig. 3. This preliminary testing confirmed that the fraction of slippage remains reasonably constant up to 2 whole revolutions. Accordingly, all subsequent tests and measurements were undertaken using $N=0.25$ revolutions where this condition was selected because the lines used for the measurements tended to become less distinct at larger numbers of revolutions.

The results from a series of tests on the three model materials are recorded in Fig. 4 for rotation speeds of (a) 0.5 and (b) $1.0 \mathrm{rpm}$. Inspection of these plots leads to several conclusions. First, the slippage fraction increases with increasing speed of rotation in the torsional straining. Thus, both plots are similar but the values recorded at $1.0 \mathrm{rpm}$ tend to be displaced to the right to slightly larger pressures. Second, the slippage fraction decreases with increasing applied pressure so that the problem of slippage becomes less significant, and may even disappear, when the pressure is high. Third, the slippage fraction is dependent upon the material used for HPT processing. In the present experiments, the slippage was a minimum for high-purity $\mathrm{Al}$, slightly greater for high-purity $\mathrm{Cu}$ and the largest amounts of slippage were recorded for the pure Fe. 


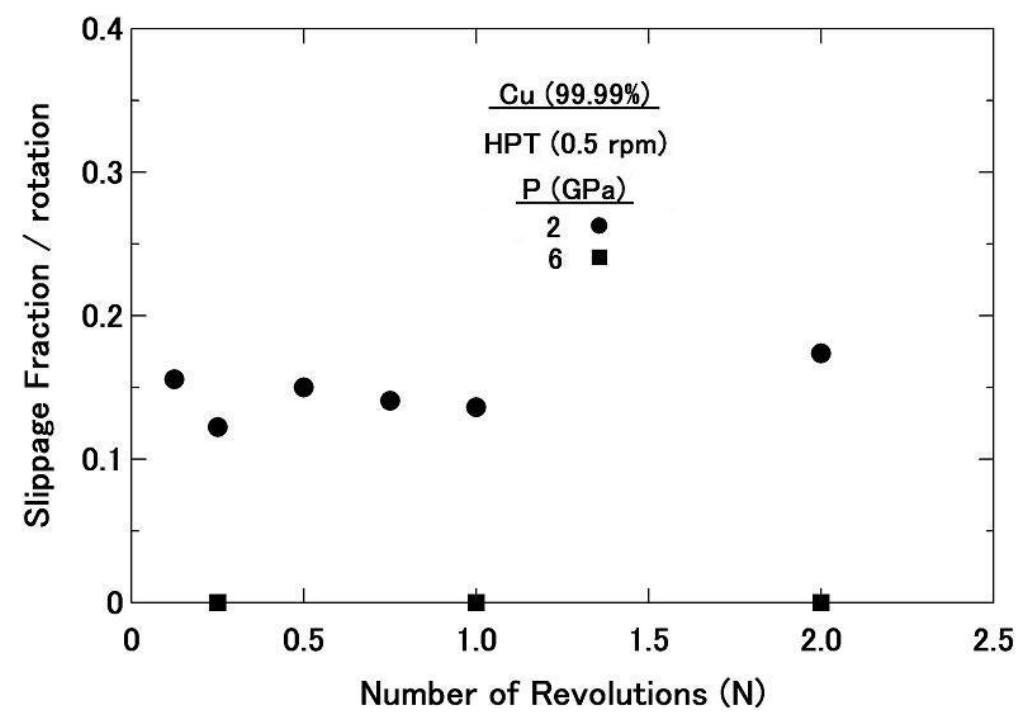

Fig. 3 Slippage fraction versus number of revolutions for high-purity $\mathrm{Cu}$ processed at $0.5 \mathrm{rpm}$ under imposed pressures of 2.0 and 6.0 GPa.
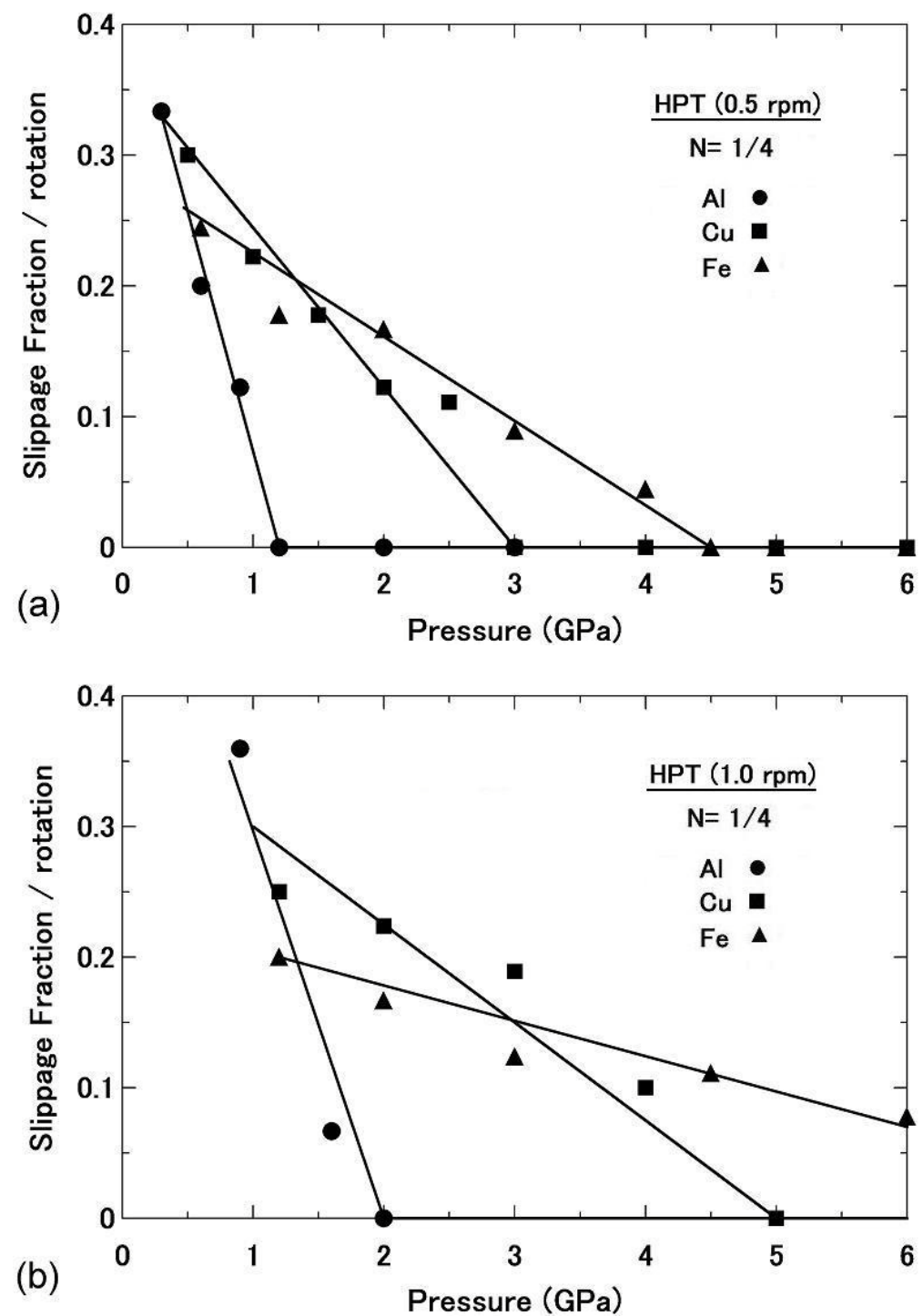

Fig. 4 Slippage fraction versus imposed pressure for the three model materials tested through 0.25 revolutions at rotational speeds of (a) 0.5 and (b) $1.0 \mathrm{rpm}$. 
Many of the HPT experiments conducted to date have used aluminum or aluminum-based alloys and the present results show that slippage is relatively unimportant in aluminum at least at and above an imposed pressure of $\sim 2 \mathrm{GPa}$. Although there is more slippage in copper, there is again no significant slippage when using an imposed pressure of $5 \mathrm{GPa}$. For pure iron the slippage fraction is reduced to zero at $4.5 \mathrm{GPa}$ for $0.5 \mathrm{rpm}$ but it remains at a level of $\sim 0.07$ at $1.0 \mathrm{rpm}$ even when using an imposed pressure of $6 \mathrm{GPa}$. These results show, therefore, there is a tendency for the amount of slippage to increase with increasing hardness. Furthermore, the results suggest the HPT processing of pure Fe is most accurately conducted by using a relatively slow rotation speed. This is an important limitation which should be taken into consideration when examining experimental data reported for iron and steel [31-37].

It is important to recognize that the present results were recorded using a set of new anvils in the HPT facility where these anvils were carefully fabricated with nitrified and roughened surfaces. It is reasonable to anticipate that the recorded slippage fractions may be larger if the anvils are prepared in different ways or if their surfaces begin to become less roughened through continuous use. Thus, both the surface roughness and the hardness appear to be important factors influencing the extent of slippage. The present results also provide a clear demonstration that the degrees of slippage vary between different materials even when using the same processing conditions. All of these findings suggest that it may be advisable, in any critical evaluation of the significant parameters in HPT, to take careful measurements of the slippage fractions both before and after any extended run of processing by HPT.

In summary, the present investigation provides significant new information on the role of disk slippage during processing by HPT. The results show the extent of any slippage depends critically upon the material. Very little slippage is experienced in aluminum, there is slightly more slippage in copper but slippage starts to become significant when testing pure iron. For all materials, the significance of slippage increases both at faster rotational speeds and at lower imposed pressures.

The pure Fe used in this investigation was supplied by the Nippon Steel Corporation for a study of "Materials Science of Ultrahigh Plastic Strain" through the Iron and Steel Institute of Japan (ISIJ). One of the authors (KE) thanks the Islamic Development Bank for a scholarship. This work was supported in part by the Light Metals Educational Foundation of Japan, in part by a Grant-in-Aid for Scientific Research from the Ministry of Education, Culture, Sports, Science and Technology of Japan in the Priority Area "Giant Straining Process for Advanced Materials Containing Ultra-High Density Lattice Defects" and in part by the National Science Foundation of the United States under Grant No. DMR-0243331.

[1] R.Z. Valiev, R.K. Islamgaliev, I.V. Alexandrov, Prog. Mater. Sci. 45 (2000) 103.

[2] R.Z. Valiev, Y. Estrin, Z. Horita, T.G. Langdon, M.J. Zehetbauer, Y.T. Zhu, JOM 58 (4) (2006) 33.

[3] R.Z. Valiev, T.G. Langdon, Prog. Mater. Sci. 51 (2006) 881. 
[4] A.P. Zhilyaev, T.G. Langdon, Prog. Mater. Sci. 53 (2008) 893.

[5] A.P. Zhilyaev, B.K. Kim, G.V. Nurislamova, M.D. Baró, J.A. Szpunar, T.G. Langdon, Scripta Mater. 48 (2002) 575.

[6] V.V. Stolyarov, R.Z. Valiev, In: Nanomaterials by Severe Plastic Deformation (M.J. Zehetbauer and R.Z. Valiev, eds,), p. $125 . \quad$ Wiley-VCH, Weinheim, Germany (2004).

[7] I.V. Alexandrov, Y.T. Zhu, T.C. Lowe, R.K. Islamgaliev, R.Z. Valiev, Nanostruct. Mater. 10 (1998) 45.

[8] V.V. Stolyarov, Y.T. Zhu, T.C. Lowe, R.K. Islamgaliev, R.Z. Valiev, Mater. Sci. Eng. A282 (2000) 78.

[9] A.R. Yavari, W.J. Botta, C.A.D. Rodrigues, C. Cardoso, R.Z. Valiev, Scripta Mater. 46 (2002) 711.

[10] J. Sort, A.P. Zhilyaev, M. Zielinska, J. Nogués, S. Suriñach, J. Thibault, M.D. Baró, Acta Mater. 51 (2003) 6385.

[11] Z. Lee, F. Zhou, R.Z. Valiev, E.J. Lavernia, S.R. Nutt, Scripta Mater. 51 (2004) 209.

[12] W.J. Botta, J.B. Fogagnolo, C.A.D. Rodrigues, C.S. Kiminami, C. Bolfarini, A.R. Yavari, Mater. Sci. Eng. A375-377 (2004) 936.

[13] E. Menéndez, J. Sort, V. Langlais, A. Zhilyaev, J.S. Muñoz, S. Suriñach, J. Nogués, M.D. Baró, J. Alloys Comp. 434-435 (2007) 505.

[14] Y. Kusadome, K. Ikeda, Y. Nakamori, S. Orimo, Z. Horita, Scripta Mater. 57 (2007) 751.

[15] T. Tokunaga, K. Kaneko, K. Sato, Z. Horita, Scripta Mater. 58 (2008) 735.

[16] T. Tokunaga, K. Kaneko, Z. Horita, Mater. Sci. Eng. A 490 (2008) 300.

[17] A.P. Zhilyaev, A.A. Gimazov, G.I. Raab, T.G. Langdon, Mater. Sci. Eng. A486 (2008) 123.

[18] A.P. Zhilyaev, S. Swaminathan, A.A. Gimazov, T.R. McNelley, T.G. Langdon, J. Mater. Sci. (2008) in press.

[19] M.T. Pérez-Prado, A.A. Gimazov, O.A. Ruano, M.E. Kassner, A.P. Zhilyaev, Scripta Mater. 58 (2008) 219.

[20] Y. Ivanisenko, A. Kilmametov, H. Rösner, R.Z. Valiev, Int. J. Mater. Res. 99 (2008) 36.

[21] J.Y. Huang, Y.T. Zhu, X.Z. Liao, R.Z. Valiev, Phil. Mag. Lett. 84 (2004) 183.

[22] Á. Révész, S. Hóbor, J.L. Lábár, A.P. Zhilyaev, Z. Kovács, J. Appl. Phys. 100 (2006) 103522.

[23] S. Faghihi, F. Azari, A.P. Zhilyaev, J.A. Szpunar, H. Vali, M. Tabrizian, Biomaterials 28 (2007) 3887.

[24] G. Sakai, K. Nakamura, Z. Horita, T.G. Langdon, Mater. Sci. Eng. A406 (2005) 268.

[25] Z. Horita, T.G. Langdon, Scripta Mater. 58 (2008) 1029.

[26] Y. Harai, Y. Ito, Z. Horita, Scripta Mater. 58 (2008) 469.

[27] C. Xu, Z. Horita, T.G. Langdon, J. Mater. Sci. (2008) in press.

[28] A.P. Zhilyaev, T.R. McNelley, T.G. Langdon, J. Mater. Sci. 42 (2007) 1517.

[29] Y. Ito, Y. Harai, T. Fujioka, K. Edalati, Z. Horita, Mater. Sci. Forum 584-586 (2008) 191.

[30] Y. Todaka, Y. Miki, M. Umemoto, C. Wang, K. Tsuchiya, Mater. Sci. Forum 584-586 (2008) 597.

[31] R.Z. Valiev, Yu.V. Ivanisenko, E.F. Rauch, B. Baudelet, Acta Mater. 44 (1996) 4795.

[32] F. Wetscher, A. Vorhauer, R. Stock, R. Pippan, Mater. Sci. Eng. A387-389 (2004) 809.

[33] A. Vorhauer, R. Pippan, Scripta Mater. 51 (2004) 921.

[34] Yu.V. Ivanisenko, R.Z. Valiev, H.J. Fecht, Mater. Sci. Eng. A390 (2005) 159.

[35] F. Wetscher, A. Vorhauer, R. Pippan, Mater. Sci. Eng. A410-411 (2005) 213.

[36] F. Wetscher, R. Pippan, Phil. Mag. 86 (2006) 5867.

[37] F. Wetscher, R. Pippan, S. Strum, F. Kauffmann, C. Scheu, G. Dehm, Metall. Mater. Trans. 37A (2006) 1963. 